\title{
From the office to the pub: The role of smoking- relevant contexts and cue-elicited urge to smoke
}

Citation for published version (APA):

Thewissen, R., van der Meijden, V. A. F., Havermans, R. C., van den Hout, M. A., \& Jansen, A. T. M. (2008). From the office to the pub: The role of smoking-relevant contexts and cue-elicited urge to smoke. European Addiction Research, 14(4), 198-205. https://doi.org/10.1159/000141644

Document status and date:

Published: 01/01/2008

DOI:

10.1159/000141644

Document Version:

Publisher's PDF, also known as Version of record

Document license:

Taverne

Please check the document version of this publication:

- A submitted manuscript is the version of the article upon submission and before peer-review. There can be important differences between the submitted version and the official published version of record.

People interested in the research are advised to contact the author for the final version of the publication, or visit the DOI to the publisher's website.

- The final author version and the galley proof are versions of the publication after peer review.

- The final published version features the final layout of the paper including the volume, issue and page numbers.

Link to publication

\footnotetext{
General rights rights.

- You may freely distribute the URL identifying the publication in the public portal. please follow below link for the End User Agreement:

www.umlib.nl/taverne-license

Take down policy

If you believe that this document breaches copyright please contact us at:

repository@maastrichtuniversity.nl

providing details and we will investigate your claim.
}

Copyright and moral rights for the publications made accessible in the public portal are retained by the authors and/or other copyright owners and it is a condition of accessing publications that users recognise and abide by the legal requirements associated with these

- Users may download and print one copy of any publication from the public portal for the purpose of private study or research.

- You may not further distribute the material or use it for any profit-making activity or commercial gain

If the publication is distributed under the terms of Article $25 \mathrm{fa}$ of the Dutch Copyright Act, indicated by the "Taverne" license above, 


\title{
From the Office to the Pub: The Role of Smoking-Relevant Contexts and Cue-Elicited Urge to Smoke
}

\author{
Roy Thewissen ${ }^{a, b}$ Valerie A.F. van der Meijden ${ }^{b}$ Remco C. Havermans ${ }^{b}$ \\ Marcel van den Hout ${ }^{c}$ Anita Jansen ${ }^{b}$ \\ Departments of a Medical, Clinical and Experimental Psychology and ${ }^{b}$ Experimental Psychology, \\ Maastricht University, Maastricht, and 'Department of Clinical Psychology, Utrecht University, Utrecht, \\ The Netherlands
}

\section{Key Words}

Smoking-relevant contexts $\cdot$ Cue exposure, smoking .

Differential conditioning $\cdot$ Urge, smoking $\cdot$ Smoking policy

\begin{abstract}
The present study investigates how environmental contexts can affect cue-elicited urge to smoke. A total of 33 smokers were repeatedly presented with a cue predicting smoking and a cue predicting no smoking in one room and the effect of context change in a different room was assessed. Results endorsed earlier findings that a cue predicting smoking availability elicited more urge to smoke than a cue predicting smoking unavailability. Furthermore, this study shows that a context switch from a low smoking-relevant room to a high smoking-relevant room reduces the learned differential urge responding between the two availability cues. These findings are discussed in relation to the role that smoking-relevant contexts play in the generalization of differential urge responding after a context switch. Furthermore, implications for government policies on smoking and clinical issues are discussed.

Copyright $\odot 2008$ S. Karger AG, Basel
\end{abstract}

\section{Introduction}

Smoking or rather the prohibition of smoking in public areas is nowadays a 'burning issue'. The increasing cost of health care as well as the implications of smoking for the economy has prompted government bodies to introduce more stringent anti-smoking legislation. For example, recently introduced legislation prohibiting smoking in public places, such as the work environment, has been implemented in many European countries. Interestingly, recent advances in the science of smoking addiction and treatment suggest that such a policy of restricting the number of environments where smoking is allowed may actually be highly beneficial in limiting the number of smokers who relapse.

Smokers consistently report higher levels in their urge to smoke when exposed to smoking-related cues $[1,2]$. This phenomenon of cue-elicited urge to smoke has been studied with the cue reactivity paradigm that is based on the theoretical framework of Pavlovian conditioning [3]. According to this theory, stimuli or cues become associated with smoking and come to act as conditioned stimuli (CSs) predicting the occurrence of smoking (the unconditioned stimulus, US) and eliciting both conditioned physiological and psychological responses (conditioned

Roy Thewissen

Department of Medical, Clinical and Experimental Psychology and Department of Experimental Psychology, Faculty of Psychology, Maastricht University, P.O. Box 616 NL-6200 MD Maastricht (The Netherlands)

Tel. +31 43388 2476, E-Mail r.thewissen@psychology.unimaas.nl 
responses, CRs), termed cue reactivity. Although a wide variety of measurements to assess cue reactivity have been conducted in the addiction research field, self-reported urge to use a drug has been found to be a more robust and cue-specific measure than psychophysiological responses [1]. Furthermore, subjectively experienced urge to smoke is a prominent aspect of smoking-related cue reactivity that plays an important role in the maintaining of and (re)lapsing into smoking addiction [4-6].

The cue reactivity paradigm has been adopted by many researchers to study different aspects of cue-induced processes and responses in addicts. One factor that could influence cue-elicited urge to use a drug is the availability of drugs. The influence of the perceived availability of drugs as a moderator of urge or craving has been studied by several researchers. In their review of these studies, Wertz and Sayette [7] conclude that nicotine-, alcohol-, and cocaine and opiate-dependent persons consistently report stronger urge when they perceive their drug as being available for use than when this is not the case.

When can drugs be perceived as being available? Of course, direct drug-related cues may function as such a signal for drug use, but within certain contexts prohibiting drug use these drug-related cues are less meaningful. For example, seeing a person smoke a cigarette at their office window does not elicit an urge to smoke because smoking inside the office building is not allowed; however, if the same person goes out for lunch and again sees somebody smoke a cigarette, this will elicit an urge to smoke because smoking outside in the open is allowed. Thus, cue reactivity depends on the accessibility or availability of smoking signalled by other cues in the environment. Carter and Tiffany [8] and Wertz and Sayette [7] have argued that such contextual control of urge depends on its function signalling an opportunity for drug use or the need to abstain. It is likely that such a signalling function is acquired through Pavlovian conditioning, i.e., learning an association between environmental context and smoking. Indeed, Conklin [9] demonstrated that distal smoking cues, such as a smoking-related environment, elicit smoking urge just as well as more proximal smoking cues such as cigarettes, a lighter or an ashtray. Likewise, certain contexts being associated with the absence of smoking might function as conditioned inhibitors, inhibiting any urge to smoke.

The influence of environments on cue-elicited urge to smoke was also investigated by Thewissen et al. [10]. They repeatedly exposed smokers to an unavailability cue (e.g., a yellow serving tray) predicting no smoking and an availability cue (e.g., a blue serving tray) paired with the opportunity to smoke in a particular environmental context. Participants rapidly came to show differential urge responding, i.e., they reported a stronger urge to smoke when exposed to the availability cue than when exposed to the unavailability cue. After this learning phase, smokers were tested for generalization of differential cue-elicited urge in another environmental context and it was found that the availability cues did not lose their predictive value in another environment, i.e., the urge to smoke was still higher following the availability cue. Thus, the meaning of the cues that was learned in one environmental context could generally be applied within a different context. The environmental contexts that were used differed in a physical sense, but both contexts bore very little relevance to smoking, i.e., participants evaluated the rooms as environments that did not remind them of places where they would normally smoke. It may be argued that a change from one low smoking-relevant environment to another may not be meaningful enough regarding the availability of smoking and, thus, did not attenuate the differential urge responding to the availability cues. Therefore, it is conceivable that a context change from a low to particularly a high smoking-relevant setting will reduce the differential urge responding between availability cues (i.e., loss of generalization), as a high smoking-relevant context in itself may signal smoking availability and hence increase the urge to smoke regardless of the presence of other more proximal cues.

The aim of the present experiment was to determine whether a change in the environmental context, using high versus low smoking-relevant contexts, reduces the differential urge responding between availability cues. This may provide relevant information on the influence of context on the motivation to smoke. If high smokingrelevant contexts promote the urge to smoke, but low smoking-relevant contexts do not, creating more of these latter contexts with a non-smoking policy would be beneficial for both non-smokers and smokers. Similar to the procedure of Thewissen et al. [10], smokers were exposed to their smoking cues after the presentation of either an availability or an unavailability cue (signalled by a blue vs. a yellow serving tray) in either a low or high smokingrelevant environment. After this acquisition phase, smokers were tested both in a low and a high smoking-relevant setting. It was expected that (1) urge to smoke would be higher when the availability cue rather than the unavailability cue was given; (2) urge responses would be stronger when smoking cues were presented than when they were not; (3) urge responses to the smoking cues would 
be stronger if the 'availability cue' was given than if the 'unavailability cue' was given; (4) after a change in the environmental context the difference in conditioned urge response between the 'unavailability cue' and the 'availability cue' is reduced (loss of generalization), and significantly more so after a switch from a low to a high smoking-relevant setting than after a switch from a high to a low smoking-relevant setting.

\section{Subjects and Method}

\section{Participants}

The participants were 33 smokers ( 23 females, 10 males; mean age $=21.70$ years, $\mathrm{SD}=2.57$, range $=18-27)$ who were recruited personally or responded to advertisements posted at Maastricht University. Only subjects who had smoked for at least 2 years, with a minimum of 5 cigarettes a day, were allowed to participate in the present study. Participants were generally light smokers as indicated by the average score of 2.94 (SD $=1.93$ on the revised $\mathrm{Fa}$ gerström Test for Nicotine Dependence (FTND) [11]. Nine participants (27\%) reported smoking 10 or fewer cigarettes a day, 22 (67\%) between 11 and 20 cigarettes, 1 (3\%) between 21 and 30 cigarettes and 1 (3\%) more than 31 cigarettes. Participants had to abstain from smoking $2 \mathrm{~h}$ prior to testing. This abstinence period was chosen in order to prevent floor or ceiling effects of the urge to smoke during the experiment. The study protocol was approved by the Standing Ethics Committee of our faculty.

\section{Setting}

The experiment was carried out in two specially designed rooms at Maastricht University. The two rooms were located in two different department buildings and were made to look distinctly different. One room was arranged to look like a typical office, while the other room was arranged in such a way that it resembled a typical pub setting. The office room was furnished with two desks, two computers, office materials (e.g., pens, paper, phones, decor), a red carpet, red office chairs, a plant and a window. The other room, the pub environment, was equipped with a counter/bar with a tap, three bar stools, six wooden tables each with two or more chairs, typical pub supplies (e.g., beer glasses, ashtrays, beer mats, serving trays, hi-fi stereo), shaded orangecoloured lights, alcohol advertisement posters and no window. The two rooms were further differentiated by using different odours: in the pub the scent of alcohol and tobacco was used, while the office room was scented with the perfume 'After Tobacco Air' (Ambi Pur, Veenendaal, The Netherlands). Respiratory tubes were connected to a ventilator in the ceiling of the rooms in order to instantly remove the smell of fresh cigarette smoke from the experimental room.

\section{Measures}

Pre-Acquisition Phase. A self-assessment bipolar visual analogue scale (VAS) with a 0 - to $100-\mathrm{mm}$ range was used to measure each of the six smoking-relevant characteristics in both rooms, namely (1) valence of the room ('In this room, I feel ...' ranging from 0 '... very unpleasant/negative' to 10 '... very pleasant/positive'); (2) subjective arousal ('At this moment, I feel ...' ranging from 0 '... very relaxed' to 100 '... very tense'); (3) urge to smoke ('At this moment, I feel ...' ranging from 0 '.... no urge to smoke at all' to 100 '... an almost irresistible urge to smoke'); (4) reference to a smoking context ('This room makes me think ... of a room in which I smoked' ranging from 0 '... very little to not at all' to 100 '... very much'); (5) perceived control of smoking ('If at this moment I would be offered a cigarette, I would be ... able to refuse' ranging from 0 '... definitely not' to 100 '... definitely'), and (6) expectation of availability to smoke ('In this room I expect to be ... allowed to smoke' ranging from 0 'definitely not' to 100 '... definitely'). Finally, another VAS was used to rate to which extent participants found the two rooms different from each other ('The first room differs ... from the second room' ranging from 0 '... to a small extent' to 100 '... to a large extent').

Acquisition and Test Phase. A 100-mm VAS was used to measure the subjective craving to smoke in each room before and during the presentation of the smoking cues. This VAS was accompanied by the statement 'At this moment, I feel ...' ranging from 0 '... no urge to smoke at all' to 100 '... an almost irresistible urge to smoke?

\section{Procedure}

Participants were asked to refrain from smoking for $2 \mathrm{~h}$ prior to the experiment. On arrival, participants received an introduction to the study and completed an informed consent form in the waiting room. After the introduction the content of carbon monoxide (CO in $\mathrm{ppm}$ ) in their end-expired air was measured and they completed the FTND Questionnaire. Next, they were taken to two rooms for a pre-acquisition session. They were instructed to relax for $1 \mathrm{~min}$ and to pay attention to the features of the room and to note what they felt and experienced at that moment. Then they completed a questionnaire in which they rated 'expectation of availability to smoke'; 'reference to a smoking context'; 'urge to smoke'; 'control of smoking'; 'valence of the room', and 'subjective arousal'. After a 5-min break, the same was done for the other room. Another VAS was used to measure the extent to which participants evaluated the two rooms as being different. Again, after a short break of $5 \mathrm{~min}$, the participants were taken to the room where the acquisition phase would take place. (The order of exposure to these two rooms was counterbalanced between subjects.)

The procedure for the acquisition phase was set up according to the model established by Thewissen et al. [10]. Participants were randomly assigned to either the 'pub' or the 'office' for acquisition. At the start of the acquisition phase, the participants were informed about the significance of the colours blue and yellow within the context of which they would be exposed to their smoking cues. As in Dols et al. [12], a belief neutralization was given with the instructions of the significance of the blue and yellow serving tray. The participants were read a statement informing them that research has found contradicting results with regard to the urge-eliciting capacity of smoking-related contexts and non-smoking-related contexts: 'Some research has found that contexts in which one is allowed to smoke generate more urge to smoke because of the expectation to smoke in the near future. And other research has found that contexts in which one is not allowed to smoke elicit more urge to smoke because of the fact that smoking restrictions make it more appealing to smoke.' This was done for all the participants of this experiment. (For a more detailed description of the belief neutralization procedure we refer to Dols et al. [12].) 
Table 1. Mean $( \pm S D)$ scores on smoking-relevant measures for the 'pub' and the 'office' contexts

\begin{tabular}{|c|c|c|c|c|c|c|}
\hline & Valence & Arousal & Urge & Reference & Control & Expectancy \\
\hline 'Pub' & $76.45 \pm 12.79$ & $24.39 \pm 15.61$ & $57.24 \pm 15.90$ & $81.18 \pm 20.39$ & $45.42 \pm 28.88$ & $81.90 \pm 17.53$ \\
\hline 'Office' & $59.00 \pm 14.54$ & $34.76 \pm 15.27$ & $38.67 \pm 15.57$ & $20.33 \pm 17.08$ & $61.94 \pm 26.26$ & $19.18 \pm 19.48$ \\
\hline
\end{tabular}

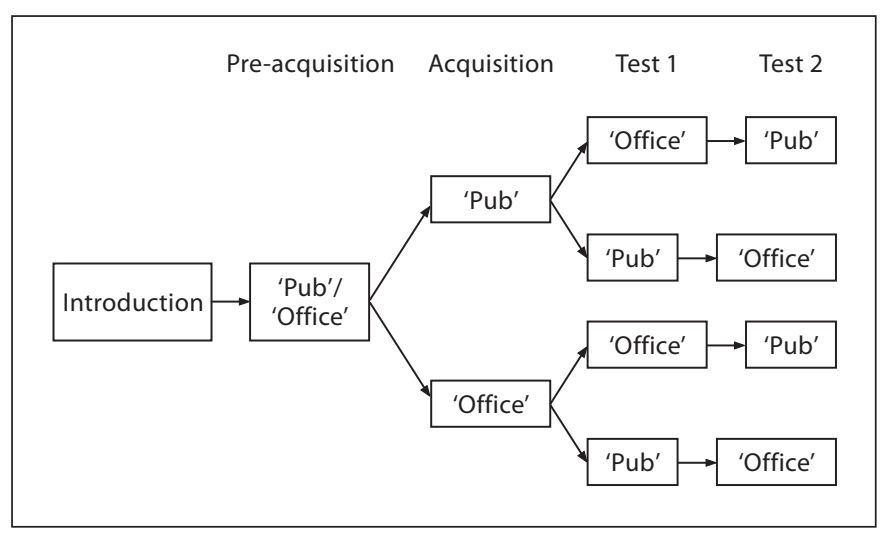

Fig. 1. Design representing the three main phases of the experiment: pre-acquisition, acquisition and test. Pre-acquisition took place in the 'pub' as well as in the 'office' (counterbalanced across participants). Acquisition took place in the 'pub' for one half of the participants $(\mathrm{n}=16)$ and in the 'office' for the other half $(\mathrm{n}=$ 17). During the test, the participants were further divided into two counterbalanced groups: one group was tested first in the 'office' and subsequently in the 'pub', while the other group was tested first in the 'pub' and subsequently in the 'office'.

Seated at a table, the participants were then presented with the serving tray (blue or yellow) and instructed to pay attention to its colour and to note their feelings and thoughts. After approximately $30 \mathrm{~s}$, the experimenter presented the participants with a VAS on which they were instructed to rate their urge to smoke. Then the participants were exposed to smoking cues (favourite brand of cigarettes, ashtray and lighter). These smoking cues were presented on the serving tray. The participants were instructed to handle the cues for approximately $30 \mathrm{~s}$. They were instructed to touch the cigarette, smell it, place it between their lips (without being allowed to sham smoke) and hold a burning lighter near the cigarette (without being allowed to light it). Then the second VAS assessment of urge took place, followed by the occurrence or nonoccurrence of smoking. If the participants were allowed to smoke (availability situation), they were instructed to take one puff and exhale the smoke through a respiratory tube. In the unavailability situation, participants were instructed to take the cigarette between their lips and hold a burning lighter to the cigarette, but were not allowed to smoke it. Each participant was put in three availability and three unavailability situations that were presented in a pseudo-random order with no more than two of the same types of situation in succession. The intertrial interval was set at approximately 3 min during which the participants were allowed to read a magazine. Availability cues (i.e., coloured serving trays) were always presented without smoking cues during the first part of the trial because of possible carry-over effects of urge responses in cue reactivity procedures.

The testing phase took place in the two rooms after a 5 -min break. There the participants were again presented with the two availability cues (blue and yellow serving tray; 1 trial each, order counterbalanced between participants) and completed the urge VAS, followed by additional exposure to the smoking cues and again the urge VAS. After a 5-min break the participants were again tested in the other room in a similar manner (counterbalanced between participants). Upon completion of the experiment, participants were fully debriefed and received money (EUR 15.00) or course credits (fig. 1).

\section{Statistics}

For all analyses, a rejection criterion of 0.05 was used, unless indicated otherwise. Huynh-Feldt epsilon corrections and corresponding adjustments to the degrees of freedom are reported for all the following analyses of variance (ANOVAs) in which the assumption of sphericity was violated.

\section{Results}

\section{Pre-Acquisition}

The two room contexts differed significantly with regard to all aspects of smoking-relevant characteristics. That is, the 'pub' context was evaluated by the participants as more positive, less arousing, eliciting more urge to smoke, referring to a higher extent to a smoking context, bringing about less control over smoking, and generating a much higher expectation of availability of smoking than the 'office' context $(5.24<\mathrm{t}<15.17$; d.f. $=32$; $\mathrm{p}<0.05)$. Furthermore, the participants indicated that these environmental contexts differed to a large extent ('difference between rooms': mean $=85.49$; $\mathrm{SD}=10.04$; $\mathrm{t}=48.91$; d.f. $=32 ; \mathrm{p}<0.01)$. Table 1 displays the mean scores for the two contexts on all the measured indices of smoking relevance.

Thus, the 'pub' can be considered as a context with high smoking-relevant characteristics, whereas the 'office' can be considered as a context with low smokingrelevant characteristics. 


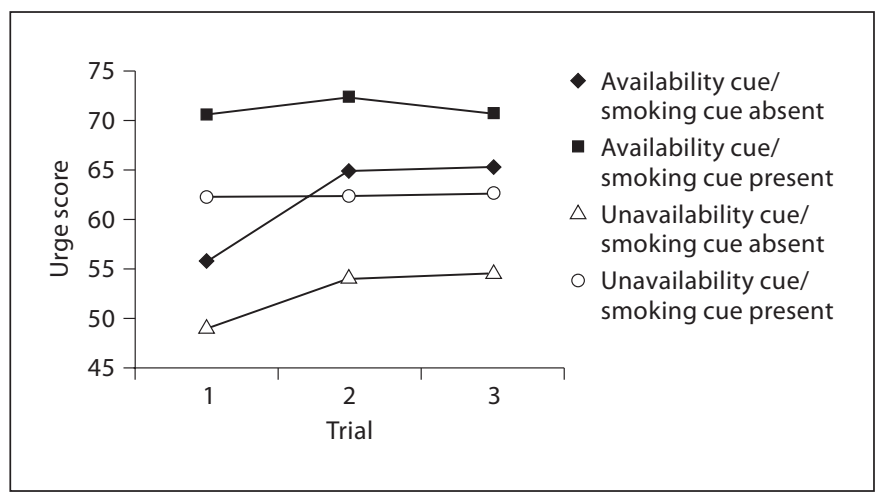

Fig. 2. Effects of availability cues and smoking cues on urge to smoke during the acquisition phase.

\section{Acquisition}

During the acquisition phase, there were 3 trials with each availability cue (yellow and blue serving tray), and during each trial, the availability cues were presented alone and with smoking cues. Thus, during acquisition, there were 12 measurements of urge. A smoking cue (present vs. absent) $\times$ availability cue (availability cue vs. unavailability cue $) \times$ trial $(1,2$ or 3$)$ ANOVA was performed for the acquisition phase.

Hypothesis 1: Urge to smoke is higher given the availability cue than given the unavailability cue. The effects of availability cues and smoking cues during the acquisition phase are depicted in figure 2. As hypothesized, the participants exposed to a serving tray predicting the occurrence of smoking (i.e., the availability cue) reported a stronger urge to smoke than when exposed to a serving tray predicting the omission of smoking (i.e., the unavailability cue) $[\mathrm{F}(1,32)=29.67, \mathrm{p}<0.01]$. Thus, the availability cues acquired the ability to differentially elicit urge responding.

Hypothesis 2: Urge to smoke is higher when smoking cues are presented than when they are not presented. The overall test revealed a significant main effect of smoking cues $[\mathrm{F}(1,32)=58.87, \mathrm{p}<0.01]$. Smokers reported higher urge when exposed to their smoking cues than when not exposed to them, irrespective of availability cues.

Hypothesis 3: Urge responses to smoking cues are higher given the availability cue than given the unavailability cue. No availability cue $\times$ smoking cue interaction was revealed by the overall test $[\mathrm{F}(1,32)<1]$. The urge-inducing effect of the smoking cues was the same for the availability cue as for the unavailability cue.
Effect of Trial. A main effect of trial was found indicating an overall increase of urge over trials $[\mathrm{F}(2,64)=4.02$, $\mathrm{p}<0.05]$. More specifically, analyses revealed a significant interaction effect of smoking cue $\times$ trial $[\mathrm{F}(2,64)=$ $10.67, \mathrm{p}<0.01]$. To further examine this interaction, separate post hoc tests were conducted with trial as the independent variable and urge responding in the presence or absence of smoking cues as the dependent variable, using a Bonferroni-corrected rejection criterion of $\alpha=$ 0.025 . Urge responding to the presence of the smoking cues stayed at the same level from the first to the last trial $[\mathrm{F}(2,64)<1]$, while urge responding in the absence of the smoking cues increased from the first to the last trial $[\mathrm{F}(1.73,55.34)=9.51, \mathrm{p}<0.01]$. The steady increase in the urge to smoke throughout the experiment can be attributed to withdrawal-induced craving, since the participants were only allowed to smoke very little and under the strict conditions set by the experimenter (after a 2-hour pre-experimental abstinence period) towards the end of the experiment, after which they were free to smoke ad libitum.

\section{Test}

The results of the acquisition phase showed differential learning regarding the availability cues. That is, in Pavlovian terms, the availability cue (CS+), predicting the occurrence of smoking behaviour (US), became a conditioned stimulus eliciting a conditioned urge response (CR), while the unavailability cue (CS-), predicting the absence of smoking behaviour (no US), became a CS inhibiting urge responding. Thus, the data allowed for a test of generalization of acquired differential urge responding.

During the test phase, each availability cue was presented alone and with smoking cues in either the low or high smoking-relevant context. Thus, during the test there were 8 measurements of the urge to smoke. For the test phase an availability cue (availability cue vs. unavailability cue) $\times$ smoking cue (present vs. absent) $\times$ test setting (same vs. different) $\times$ smoke relevance (high smoking-relevant context vs. low smoking-relevant context) ANOVA was performed with availability cue, smoking cue and test setting as within-subject factors and smoking relevance as between-subject factor.

Hypothesis (4): After a change in an environmental context the difference in conditioned urge response between the 'unavailability cue' and the 'availability cue' is reduced (loss of generalization), significantly more so after a switch from a low to a high smoking-relevant setting ('office' to 'pub') than after a switch from a high to a low smoking- 
relevant setting ('pub' to 'office'). The effects of test setting (same vs. different from the acquisition setting) and smoking relevance (tested in the high or low smokingrelevant context) on urge to smoke in all four conditions of the test phase are depicted in figure 3. Analyses revealed a significant main effect of availability cues $[\mathrm{F}(1,31)=18.87, \mathrm{p}<0.01]$, indicating that - regardless of any environmental context switch - the availability cue still elicited a higher urge response than the unavailability cue tested. However, as expected, a significant interaction between availability cues and test setting $[\mathrm{F}(1,31)=$ $4.95, \mathrm{p}<0.05]$ revealed that the differential urge responding to the availability cues was stronger in case of no change in the environmental context. No three-way availability cue $\times$ test setting $\times$ smoking relevance interaction effect was found $[\mathrm{F}(1,31)<1]$. However, given the a priori hypothesis that a loss of the generalization of urge responding to the availability cues is particularly strong when testing in a high smoking-relevant environment, specific analyses were conducted with test setting and smoking relevance as independent variables and the urge to smoke in the case of the availability and the unavailability cues as dependent variable, using a Bonferronicorrected rejection criterion of $\alpha=0.025$. Differential urge responding between the availability cues decreased significantly $[\mathrm{F}(1,16)=6.64, \mathrm{p}<0.025]$ when a context change occurred from a low to a high smoking-relevant context, whereas this differential urge responding remained at the same level $[F(1,15)=0.82, p=0.37]$ when a context change occurred from a high to a low smokingrelevant context. Thus, these results confirm the hypothesis that switching from a low to a high smoking-relevant context induces a larger loss of generalization than when switching from a high to a low smoking-relevant context.

Further, analyses showed a significant main effect of smoking cues $[\mathrm{F}(1,31)=35.38, \mathrm{p}<0.01]$, indicating a higher urge score when smoking cues were presented than when they were absent. A smoking cue $\times$ test setting interaction effect was marginally significant $[\mathrm{F}(1,31)=$ $4.13, \mathrm{p}<0.06]$, but the smoking cue $\times$ test setting $\times$ smoking relevance interaction clearly reached significance $[\mathrm{F}(1,31)=7.91, \mathrm{p}<0.01]$. This interaction reflects a larger effect of smoking cue exposure on smoking urge when exposed to smoking cues in a high smoking-relevant environment during the test when no context change was done (same test setting), as can be inferred from figure 3. No other main or interaction effects were found (all $\mathrm{p}>0.10$ ).

Role of Smoking-Relevant Contexts and Cue-Elicited Urge to Smoke

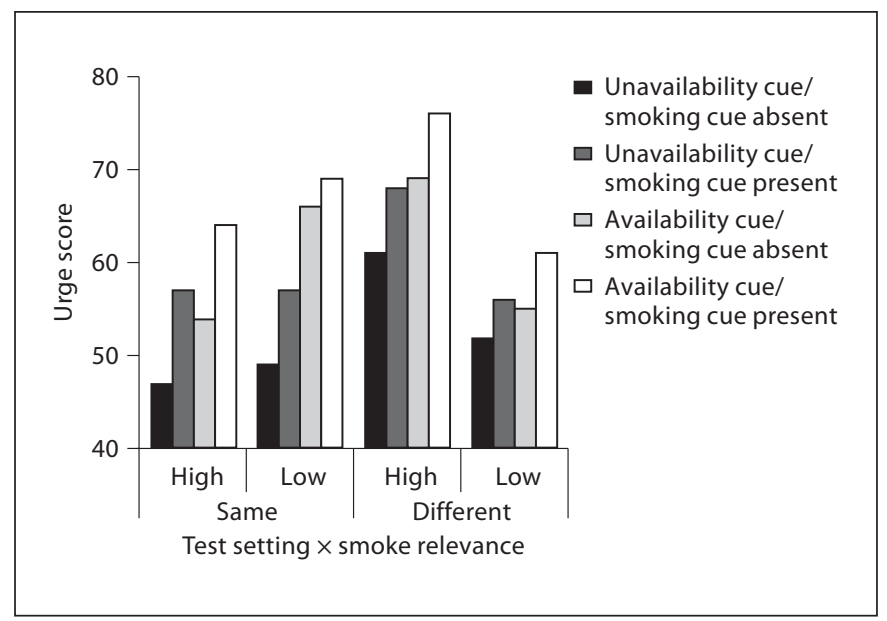

Fig. 3. Effects of test settings (same vs. different from the acquisition setting) and smoking relevance (tested in high or low smoking-relevant context) on urge to smoke in the presence or absence of the smoking cues and in the presence of the availability cues.

\section{Discussion}

As reported by Dols et al. $[12,13]$ and Thewissen et al. $[10,14]$, a cue predicting smoking availability reliably elicited a higher urge to smoke than a cue predicting the unavailability of smoking. As Thewissen et al. [10] found, smoking cues kept their ability to elicit urge responding both in case of the availability as well as the unavailability cue, although this effect of smoking cues seemed to be reduced at the last acquisition trial. The urge-inducing effect of smoking cues thus demonstrates that urge responding to these cues was not completely modulated by the availability cues. More importantly though, it was found that the availability cues differentially elicited smoking urge depending on whether they signalled either smoking opportunity or not, and that this acquired differential urge responding was lost with a switch to a high smoking-relevant environment. The present results thus confirm the hypothesis that a context switch from a low smoking-relevant context to a high smoking-relevant context reduces the learned differential urge responding between the two availability cues, respectively predicting the availability and unavailability of smoking. One could argue that participants may have had certain pre-experimental beliefs concerning the outcome of the experiment that led to experimental demand and subsequently to the present pattern of results. However, the belief neutralization procedure adopted in the present experiment was intended to limit the probability of experimental de-

Eur Addict Res 2008:14:198-205 
mand. Furthermore, empirical evidence indicates that the differential conditioning procedure, as applied in the present study, is relatively insensitive to such demands [for an extended discussion see 10; 12].

The results presented here raise the question of what role smoking-relevant contexts play in the generalization of differentially conditioned urge responding after a context switch. As suggested by Thewissen et al. [10], a context change may have to be meaningful in relation to the signalling value of availability of smoking of the availability cues. Indeed, contexts do not appear to function as simple conditioned excitors or inhibitors, as learning to differentiate between availability cues predicting the occurrence and non-occurrence of smoking did not seem to depend on context. Such differentiation was rapidly acquired in both a low and high smoking-relevant context. Further, what is learned in a high smoking-relevant context could easily be applied generally to a different low smoking-relevant context. However, when one learns this discrimination between availability cues in a low smoking-relevant context (e.g., 'office' context) and then switches to a high smoking-relevant context, in which one expects to be allowed to smoke (i.e., 'pub' context), this context switch seems to be more meaningful, hence attenuating generalization. The high smoking-relevant context appears to be a (semantic) complex stimulus providing information about smoking behaviour: smokers feel relaxed, experience higher urge to smoke and less control to refrain from smoking, and expect to be allowed to smoke. In other words, the expectation of being allowed to smoke in the high smoking-relevant context is particularly salient after a context switch from a low to a high smoking-relevant context. Thus, when there is a switch from a low to a high smoking-relevant context, the expectation of being allowed to smoke overrides the previously acquired inhibitory association between the unavailability cue and smoking behaviour.

What are the implications concerning policies on smoking in public areas? Findings in the study by Thewissen et al. [10] suggest that generally prohibiting smoking in certain public areas, and, therefore, establishing a meaning of 'the unavailability or inaccessibility of smoking', will lead to an attenuation of the urge to smoke and thus a decrease in the risk of relapse. This is indeed beneficial for both smokers and non-smokers, as the former group is less tempted to smoke, which could reduce their overall smoking rate (e.g., smoking prevalence is lowest in Finland where smoking is prohibited in most public areas [15]), while the latter group is less exposed to the hazards of passive smoking in public areas. However, the problem of tobacco addiction will not be tackled alone by interventions of this kind, as the results of the present study suggest that when smokers learn that particular contexts rule out smoking, and hence experience less urge to smoke, these effects cannot generally be applied to other high smoking-relevant contexts. These high smoking-relevant contexts can include the outdoor public areas, one's own living environment, specially equipped smoking areas, etc. Thus, despite prohibiting smoking in many public places like restaurants, shops, pubs, etc., smokers can and will find alternative means to continue smoking. It seems very likely that prohibiting smoking in particular public places will only shift the problem of smoking addiction for smokers who do not intend to quit smoking. Certainly limiting smoking in particular public areas for the sake of protecting nonsmokers from the hazards of passive smoking and lowering the smoking rate of smokers is worthwhile; government resources and efforts should also substantially focus on tackling the issue of the motivation to quit smoking. Furthermore, the findings of the present study raise the question of whether the clinical results of the treatment of smoking addiction can be extrapolated from a clinical setting/context, in which by definition smoking is prohibited (far end of low smoking-relevant context), to the personal living environment of the client, which still has strong smoking-relevant characteristics. As already shown by Thewissen et al. [14], cue exposure effects - eliminating cue-elicited urge to smoke - are limited to the context in which they are learned, demonstrating a renewal of cue-elicited urge to smoke when returning to the context in which smokers previously had learned to smoke (turning these contexts into high smoking-relevant contexts signalling smoking availability). Taken together, these results suggest that the urge attenuation effects of prohibiting smoking in any particular context are restricted to these contexts themselves but are not sufficient to entirely eliminate tobacco addiction.

An important issue that should be considered when conducting further experiments is the use of adequate high smoking-relevant contexts. In the present experiment, a 'pub' was used as a high smoking-relevant context, as in The Netherlands at the time of conducting the experiment smoking was still allowed in pubs. (As from July 2008, smoking in hotels, restaurants and pubs will be prohibited in The Netherlands.) However, in other European countries as, for example, Ireland and Italy, smoking is already prohibited in pubs and they are, therefore, no longer considered as high smoking-relevant contexts. Further, it should be noted that the participants in the 
present experiment were mainly smokers with a low to moderate level of smoking dependence and who did not intend to quit smoking at the time of testing. Future research should investigate whether the findings of the present experiment also apply to heavier smokers.

\section{Acknowledgment}

This research work was supported by Grant No. 985-10-006 from NWO-ZON Program Addiction.

\section{References}

1 Carter BL, Tiffany ST: Meta-analysis of cue reactivity in addiction research. Addiction 1999;94:327-340.

2 Niaura RS, Rohsenow DJ, Binkoff JA, Monti PM, Pedrazza M, Abrams DB: Relevance of cue reactivity to understanding alcohol and smoking relapse. J Abnorm Psychol 1988;97: $133-152$.

$\checkmark 3$ Lavez AB, Herzog TA, Brandon TH: Classical conditioning of environmental cues to cigarette smoking. Exp Clin Psychopharmacol 1999;7:56-63.

$\checkmark 4$ Killen JD, Fortmann SP: Craving is associated with smoking relapse: findings from three prospective studies. Exp Clin Psychopharmacol 1997;5:137-142.

5 Shiffman S, Paty JA, Gnys M, Kassel JA, Hickcox M: First lapses to smoking: withinsubjects analysis of real-time reports. J Consult Clin Psychol 1996;64:366-379.
6 Shiffman S, Engberg JB, Paty JA, Perz WG, Gnys M, Kassel JD, Hickcox M: A day at a time: predicting smoking lapse from daily urge. J Abnorm Psychol 1997;106:104-116.

7 Wertz JM, Sayette MA: A review of the effects of perceived drug use opportunity on self-reported urge. Exp Clin Psychopharmacol 2001;9:3-13.

8 Carter BL, Tiffany ST: The cue-availability paradigm: the effects of cigarette availability on cue reactivity in smokers. Exp Clin Psychopharmacol 2001;9:183-190.

$\checkmark 9$ Conklin CA: Environments as cues to smoke: implications for human extinction-based research and treatment. Exp Clin Psychopharmacol 2006;14:12-19.

10 Thewissen R, van den Hout M, Havermans RC, Jansen A: Context-dependency of cueelicited urge to smoke. Addiction 2005;100: 387-396.

$\checkmark 11$ Heatherton TF, Kozlowski LT, Frecker RC, Fagerström KO: The Fagerström Test for Nicotine Dependence: a revision of the Fagerström Tolerance Questionnaire. Br J Addict 1991;86:1119-1127.
12 Dols M, van den Hout M, Kindt M, Willems BW: The urge to smoke depends on the expectation of smoking. Addiction 2002;97: 87-93.

13 Dols M, Willems BW, van den Hout M, Bittoun R: Smokers can learn to influence their urge to smoke. Addict Behav 2000;25:103108 .

14 Thewissen R, Snijders SJBD, Havermans RC, van den Hout M, Jansen A: Renewal of cueelicited urge to smoke: implications for cue exposure treatment. Behav Res Ther 2006; 44:1441-1449.

15 Helakorpi S, Martelin T, Torppa J, Patja K, Vartiainen E, Uutela A: Did Finland's Tobacco Control Act of 1976 have an impact on ever smoking? An examination based on male and female cohort trends. J Epidemiol Community Health 2004;58:649-654. 